\title{
One species of seagrass cannot act as a surrogate for others in relation to providing habitat for other taxa
}

\author{
B. M. Hamilton ${ }^{1,2, *}$, P. G. Fairweather ${ }^{1,2}$, B. McDonald ${ }^{2}$ \\ ${ }^{1}$ School of Biological Sciences, Flinders University, GPO Box 2100, Adelaide, South Australia 5001, Australia \\ ${ }^{2}$ Marine Parks Project, Department of Environment and Natural Resources, GPO Box 1047, Adelaide, \\ South Australia 5001, Australia
}

\begin{abstract}
Epibiotic assemblages provide an important source of primary and secondary production in seagrass habitats. Surrogates for biodiversity, such as broad-scale habitat types, have been used in selecting marine park boundaries and zones. As a preliminary test of one assumption of surrogacy that in effect treats all seagrass species as equal, the epibiotic assemblages of pairs of seagrass species, including the regionally rare Posidonia coriacea, were sampled between homogeneous or heterospecific patches at 3 separate locations in South Australia. Three seagrass species, each with distinct morphology, had distinguishable epifaunal assemblages. Free-living epifauna showed clear selection between seagrass species with movement likely over small scales within heterospecific patches, but no such distinction was shown when the same seagrass species pair was separated rather than intermingled. Epiphytic sessile species showed less well-defined specificity among seagrass species, but there were still significant differences in epiphytic species richness. The results of this preliminary study suggest that marine conservation planning needs to consider seagrass habitat on a species-by-species basis, including how they are arranged within localised patches.
\end{abstract}

KEY WORDS: Amphibolis antarctica · Epifauna ' Epiphyte · Field surveys · Marine conservation planning $\cdot$ Posidonia coriacea $\cdot$ P. sinuosa $\cdot$ South Australia

\section{INTRODUCTION}

There is much interest in conserving marine biodiversity, but knowledge of species distributions critical to marine reserve planning is limited by a fundamental lack of data, time and funds. Thus, habitat surrogates, defined as easily measured features with distributions better known than those of their component species (Rodrigues \& Brooks 2007, Hirst 2008), have been proposed to overcome a lack of complete knowledge of species diversity. Representing habitat-level diversity in reserves is thought likely to also capture other levels of biodiversity. The range of habitats considered as surrogates for selecting marine reserves includes seagrass meadows, which are recognised as both economically and environmentally important (e.g. McArthur \& Boland 2006).

Seagrasses influence environments of coastal ecosystems (Hemminga \& Duarte 2000), acting as ecosystem engineers (Jones et al. 1994) or foundation species by providing habitat for other organisms (Hughes et al. 2009). Seagrasses also provide an important source of primary production (Hemminga \& Duarte 2000) that influences coastal food web structure. Seagrass habitat can be quite diverse, harbouring multiple levels of biodiversity, which goes on to enhance productivity and stability of seagrass ecosystems (Duffy 2006). Unfortunately, seagrass ecosystems suffer from increasing anthropogenic impacts (Waycott et al. 2009), and their key ecological 
processes (including carbon sequestration, nutrient cycling, sediment stabilisation and providing trophic links to other habitats) are under decline globally (Orth et al. 2006), requiring protection through the implementation of representative marine reserves.

One common design principle in reserve planning strives for the comprehensive inclusion of distinct biotic assemblages. Such assemblages could be associated with particular or unusual species of seagrass, such as Posidonia coriacea Kuo \& Cambridge, one of the species used in this study. P. coriacea belongs to the $P$. ostenfeldii group, 1 of 2 subgeneric groups within the genus Posidonia (Gobert et al. 2006), defined by strong vertical growth, thus forming isolated patches rather than continuous meadows (Gobert et al. 2006, Bryars et al. 2008). P. coriacea is a relatively rare seagrass species, endemic to the southern coastline of Australia (Vanderklift \& Lavery 2000), including patchy populations along the Fleurieu Peninsula of South Australia. It has long (up to $120 \mathrm{~cm}$ ), tough leaves, which grow in dense clumps (Gobert et al. 2006). Published literature on $P$. coriacea comes mainly from Western Australia, with only a few studies focusing on the epiphytic macroalgal assemblages associated with $P$. coriacea (Vanderklift \& Lavery 2000, Lavery \& Vanderklift 2002). P. sinuosa Cambridge \& Kuo has shorter, finer leaves, and grows in matting aggregations. The temperate Australian endemic seagrass Amphibolis antarctica (Labill) Sonder \& Asch. ex Asch. grows in dense matting aggregations, with its tough wiry stems ending in numerous terminal leaf clusters.

Various other organisms associate with seagrass plants. Some of these organisms utilise seagrass by attaching themselves to the hard substrate provided by leaves or stems. These epiphytes can include numerous taxa, such as algae, bryozoans, spirorbids and other sessile polychaetes, sponges, hydroids and forams. Epiphytes provide an important source of primary production, sediment production and nitrogen and nutrient cycling (Borowitzka et al. 2006) but can vary depending on a variety of factors, including abiotic (e.g. light attenuation, nutrient loads, wave energy, temperature, hydrodynamics and the substrate for attachment) and biotic (e.g. grazing pressure and propagule supply) variables (Bryars et al. 2008). Free-living epifauna also associate with seagrass and can be classified as motile animals living above the sediment but within the complex leaf and stem structure (Raz-Guzman \& Grizzle 2001). They are an important source of secondary production, especially as prey for organisms like fish higher in the food web.
In this preliminary study, we compared the abundance and diversity of leaf-associated epibiotic assemblages between 2 Posidonia species, P. sinuosa and $P$. coriacea, and with the locally co-occurring species Amphibolis antarctica along the Fleurieu Peninsula, South Australia. This preliminary research is one of only a few studies to examine the whole epibiotic assemblage between seagrasses of inherently different morphologies (Borowitzka et al. 2006). Lavery \& Vanderklift (2002) included the epiphytic macroalgae of both $P$. coriacea and A. griffithii in such a comparison from Western Australia, whilst the association between algae epiphytes, epifauna and plant material of P. sinuosa and A. griffithii was studied by Jernakoff \& Nielsen (1998). Neither study compared epibiota between different patch arrangements of their respective seagrass species, nor their potential for surrogacy. Thus, we sought to assess the potential of epibiotic surrogacy amongst the seagrasses $P$. coriacea, P. sinuosa and A. antarctica.

\section{MATERIALS AND METHODS}

\section{Site selection and descriptions}

Sampling was carried out on 12 November 2008 at 3 locations along South Australia's Fleurieu Peninsula (Fig. 1). Locations were off Maslin Beach (MB: $138^{\circ} 46^{\prime} \mathrm{E}, 35^{\circ} 24^{\prime} \mathrm{S}$ ), Silver Sands (SS: $138^{\circ} 43^{\prime} \mathrm{E}$, $35^{\circ} 30^{\prime} \mathrm{S}$ ) and Sellicks Beach (SB: $138^{\circ} 44^{\prime} \mathrm{E}, 35^{\circ} 33^{\prime} \mathrm{S}$ ). Locations were dictated by the spatial arrangement of the seagrasses in nature, with the presence of either mono- or heterospecific patches of Amphibolis antarctica, Posidonia coriacea and P. sinuosa confirmed by examining underwater video footage held by the state Department of Environment and Natural Resources.

Within each location, 3 sites were randomly selected for sampling. Sites, defined as an area within a diameter of $10 \mathrm{~m}$ from an anchoring point, contained numerous patches of seagrass. Patches did not form part of larger beds or clumps but instead appeared as plants separated by bare sand over a large spatial scale. Three patches within each site were randomly sampled.

At SS, Posidonia sinuosa and Amphibolis antarctica occurred together within 3 heterospecific patches of seagrass, with sites separated by 15 to $35 \mathrm{~m}$. At SB, 3 heterospecific patches of $P$. coriacea and $A$. antarctica were sampled, with sites separated by 17 to $22 \mathrm{~m}$. At MB, P. coriacea and A. antarctica were geographically separated by an area of bare 


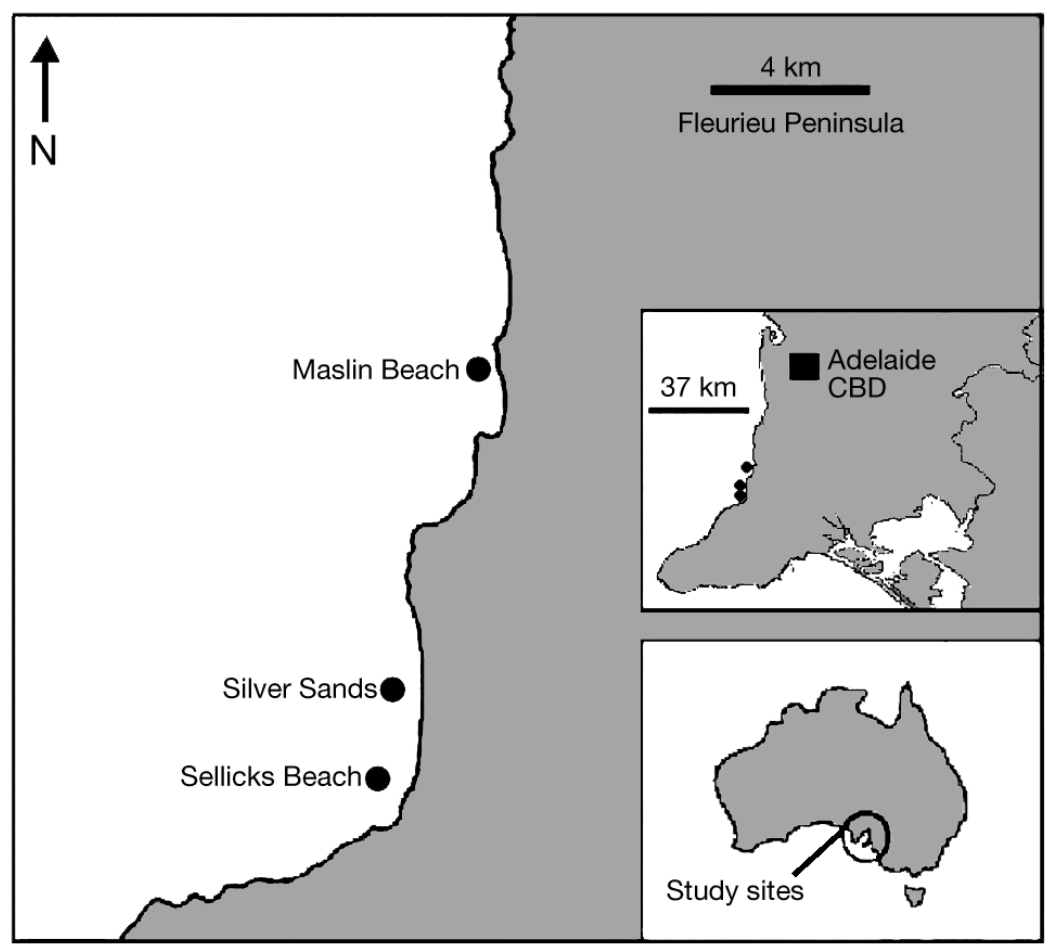

Fig. 1. Sampling locations (off Maslin Beach, Silver Sands, and Sellicks Beach) in relation to the Adelaide Central Business District (CBD), southern Fleurieu Peninsula and the rest of Australia

immediately after collection to remove excess water before freezing. Samples were stored on ice before being placed in a $-20^{\circ} \mathrm{C}$ freezer the day following collection. Two control samples (i.e. bags of the nearby water column only) were taken directly opposite each seagrass species, for every patch at SB. These procedural control samples contained no epifauna, and so were subsequently omitted from the comparison.

\section{Processing of epifauna and epiphytes}

In the laboratory, each sample was thawed and washed through a $500 \mu \mathrm{m}$ sieve before the retained contents were identified and counted for estimating abundance and diversity of all macroscopic mobile epifauna.

To sample species presence and the relative abundance of epiphytes, stem and leaves were treated as 2 separate but matched strata for the seagrass Amphibolis antarctica. Each sample

sand, measuring approximately $100 \mathrm{~m}$ wide. On either side of this bare sand, 3 sites separated by between 30 and $100 \mathrm{~m}$ were chosen, and within each site, 3 monospecific patches contained either $P$. coriacea or A. antarctica. Thus, the pairs of seagrass species at each location were either intermingled (SS, $\mathrm{SB})$ or separate $(\mathrm{MB})$.

\section{Sampling}

Due to the rarity, potential slow re-growth and unknown recovery time of Posidonia coriacea (Edgar 2001), it was imperative that the least destructive sampling be used (rather than uprooting whole plants). Thus, the number of samples was reduced to be just 2 replicates per species per patch to reduce disturbance and only the canopy assemblages associated with the distal portion of leaves were studied (thereby minimising loss of seagrass biomass). Sampling bags (polyethylene zip-lock bags measuring $25 \times 30 \mathrm{~cm}$ ) were used to cover a distal portion of plants, where the opening of the bag was shut, and then all seagrass held within was separated from the rooted plant with scissors before being zip locked. Entire samples were sieved through $500 \mu \mathrm{m}$ mesh bag therefore yielded a matched sample of freeliving epifauna and of epiphytes attached to leaves.

Following Bramwell \& Woelkerling (1984), who found no difference in the epiphytic crustose coralline assemblage between sides of the leaves in Amphibolis antarctica, epiphyte presence and abundance was calculated from the total count of each occurrence on both sides. The concave leaf morphology found on one side of Posidonia sinuosa may have an impact on its epiphytic assemblage (Trautman \& Borowitzka 1999), but for the purpose of this study, no differentiation between sides was made for either Posidonia species.

Two levels of sub-sampling were carried out due to the sheer number and volume of epiphytes on the leaves of seagrass, which would have been extremely time consuming to count and identify. All seagrass was emptied onto a sorting tray, and 5 leaves were chosen at random from each bag of Posidonia coriacea and P. sinuosa (Kendrick \& Lavery 2001). A $10 \mathrm{~cm}$ sub-section was cut from the middle of each leaf. Five leaf clusters of Amphibolis antarctica were randomly chosen per bag of $A$. antarctica. Because different-aged leaf surfaces can contain different epiphytic assemblages (Bramwell \& Woelkerling 1984), numerous leaves from each of the 5 leaf 
clusters were removed at random until the total length (end to end) of all leaves equalled at least $10 \mathrm{~cm}$ for each leaf cluster. Epiphytes were then identified and counted to determine diversity and abundance.

\section{Biomass of seagrass and epiphytes}

To determine epiphytic and seagrass biomasses, epiphytes were physically removed by scraping plant material by holding a razor blade at an angle of roughly $90^{\circ}$, before running it along the leaf's entire length. Earlier washing under a gentle stream of fresh water removed any inorganic material, such as sediment. Further care was taken to avoid the excessive inclusion of plant epidermis in epiphytic scrapings. Once all plant and epiphytic material was separated, they were weighed after drying at 75 to $80^{\circ} \mathrm{C}$ for 48 h (Kendrick \& Lavery 2001).

\section{Functional groups of epiphytes}

Due to the time, expense and difficulty involved in the identification of small and abundant epiphytic macroalgae, all epiphytic algae were identified to morphospecies and then further characterised into the functional groups proposed by Steneck \& Dethier (1994): the functional groups found included filamentous algae, foliose algae, corticated foliose algae, corticated macrophytes and articulated calcareous algae. Other non-algal epiphytes were encountered which did not fit the definitions proposed by Steneck \& Dethier (1994). These were grouped into their own functional group called 'fauna'. This faunal functional group contained a diverse range of species across numerous phyla, including a Pyura sp. ascidian (Chordata), Leucosolenia sp. sponge (Porifera), Plumularia sp. hydroid (Cnidaria), spirorbid worms (Annelida), Thairopora sp. and Lichenoporidae (Bryozoa) and Foraminifera. Counts of individual algae and fauna were combined for an estimate of abundance of each functional group.

\section{Data analysis}

In order to test the difference in epibiotic communities between seagrass species, each location was analysed separately, due to different pairs of seagrass species being found within each (although Amphibolis was found at each location) and the different arrangements of either hetero- or monospecific patches. In each case, comparing assemblages across the pair of seagrass species was the prime factor of interest, but the effects of site-to-site or patch-to-patch variation were not allowed to confound that interpretation (by estimating their effects also). SS and SB had the same experimental design, but the 2 locations differed as Posidonia sinuosa or $P$. coriacea, respectively, was the second species in the pair. The design for SS and SB was treated as a 3-factor mixed-model analysis of variance (ANOVA). The 3 factors included Sites (considered as a random factor), Species (treated as fixed) and Patches nested within Sites (random).

MB had a different, 3-factor hierarchical or nested design, where sites were separate and contained only 1 of the 2 species, either Posidonia coriacea or Amphibolis antarctica. Factors used in the design for MB included Species (fixed), Sites nested within Species (random) and Patches nested within Sites, which were nested within Species (random). SYSTAT v.11 software was used for ANOVA and to graphically represent raw or transformed univariate data for richness and abundance.

All multivariate analysis was carried out using PRIMER v.6 and PERMANOVA+ software (Clarke \& Gorley 2006, Anderson et al. 2008). Multi-dimensional scaling (MDS) ordination plots were used to represent the assemblage composition and relative abundances of all replicate samples per seagrass species. Sample points close together in 2D ordination space are similar in terms of their species and abundances, whereas points far apart share few epibiota in common. Replicate samples lacking any epibiota were removed from further analysis. Permutational MANOVA (PERMANOVA, Anderson et al. 2008) was used to test the simultaneous response of epibiota to factors in the same statistical designs as outlined above for each location. Similarity percentage (SIMPER) analysis (Clarke \& Gorley 2006) was used to determine the most consistent contributions of indicator species to the total average dissimilarity between seagrass species.

\section{RESULTS}

\section{Epifauna}

A total of 86 species of motile epifauna in 4 phyla were recorded during this study. Of the phyla, Arthropoda was the most diverse, with a total of 51 species. The second-most diverse phylum was Mol- 

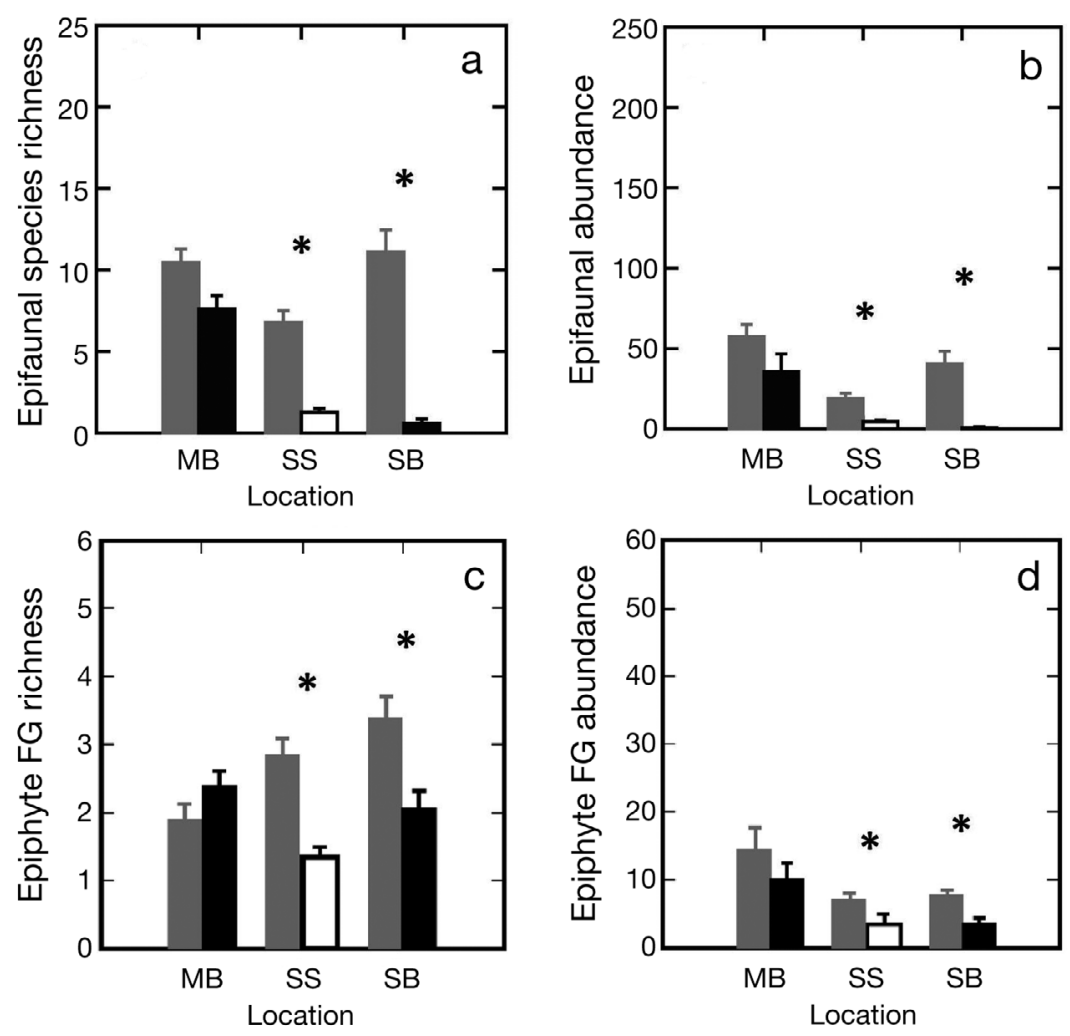

Fig. 2. Amphibolis antarctica (grey), Posidonia coriacea (black), and P. sinuosa (white). Untransformed mean (+SE) for epifaunal (a) species richness, (b) abundance, (c) functional group (FG) richness and (d) FG abundance across all locations for each species. MB: Maslin Beach, SS: Silver Sands, SB: Sellicks Beach. The $y$-axis shows the range of the raw data per sample. ${ }^{*}$ Statistical significance $(\mathrm{p}<0.05)$ between seagrass species pairs mono- and heterospecific patches (Fig. 2a). At SS and SB, both Posidonia coriacea and P. sinuosa showed significantly lower mean species richness when compared with $A$. antarctica in the same hetero-specific patches. $P$. coriacea in monospecific patches (at $\mathrm{MB}$ ) had higher species richness than heterospecific patches (at SB). The increase in species richness shown by $P$. coriacea between homogeneous and heterogeneous patches did not apply for A. antarctica (Fig. 2a).

Epifaunal abundance data showed a similar trend, where the mean abundance for Amphibolis antarctica remained comparatively high across all 3 locations, only decreasing in heterospecific patches at SS (Fig. 2b). The mean epifaunal abundance in heterospecific patches at SS and SB, containing either Posidonia coriacea or P. sinuosa, showed a significant difference when compared to $A$. antarctica. The monospecific patches of $P$. coriacea sampled at $\mathrm{MB}$ showed a large abundance of epifauna (exceeding that found in heterospecific patches of the same species at SB) but were not significantly different from $A$. antarctica at MB. lusca, with a total of 26 species, followed by Annelida with 7, and a single contribution from Chordata. Some 54 species were found exclusively on Amphibolis antarctica, 7 only on Posidonia coriacea, 2 only on $P$. sinuosa, and 23 species were found on all 3 seagrass species. Members of the Polychaeta, Gastropoda, Isopoda and Amphipoda accounted for the majority of species found exclusively on $A$. antarctica. Only a single morphospecies, a copepod from the order Harpacticoida, was recorded across all 3 seagrass species at all locations. At MB, 33 species were unique to $A$. antarctica compared to 11 unique species on $P$. coriacea, whilst 17 species were found on both. At SB, 48 unique species were found on $A$. antarctica, 2 were found solely on $P$. coriacea, and 4 species were found on both. At SS, 26 unique species were found on $A$. antarctica, 5 on $P$. sinuosa, and 4 species were shared by this pair of seagrass species.

Mean epifaunal species richness was high for Amphibolis antarctica across all locations, in both

\section{Multivariate analysis of epifauna}

In the MDS plots, the faunal assemblages at MB (Fig. 3a), SS (Fig. 3b) and SB (Fig. 3c) all showed a strong separation when analysed by seagrass species. Both MDS plots for SS and SB had acceptable stress values of 0.07 (Fig. 3b,c), whilst the MDS plot for $\mathrm{MB}$ had a higher but still acceptable stress value of 0.13 (Fig. 3a).

SIMPER analysis then revealed the key species most likely to contribute most to dissimilarity between seagrass species. Ten species, including 4 species of Amphipoda, a mitrellid gastropod, a chydorid cladoceran, harpacticoid copepods, an Apseudomorpha species, Polyplacophora sp. 1 and an Electroma species each contributed consistently (dissimilarity/ $\mathrm{SD}>1$ ) to the average dissimilarity between the seagrass species at MB. The average dissimilarity between Posidonia coriacea and Amphibolis antarctica was less than for seagrass pairs at SS and SB but still large $(78.8 \%)$. 

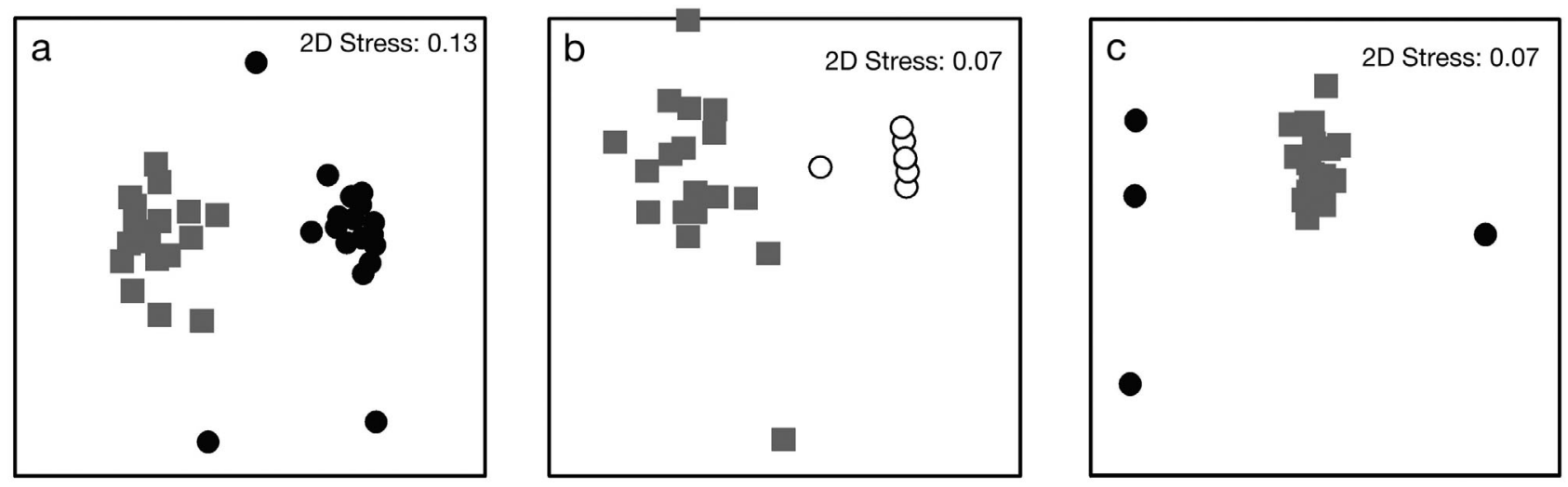

Fig. 3. Amphibolis antarctica (grey squares), Posidonia coriacea (black circles), and P. sinuosa (white circles). Multi-dimensional scaling (MDS) ordination plots of the epifaunal assemblages compared between A. antarctica and (a) P. coriacea at Maslin Beach (MB), (b) P. sinuosa at Silver Sands (SS), and (c) P. coriacea at Sellicks Beach (SB). Raw data were standardised and $\log (x+1)$ transformed. All 18 samples of $A$. antarctica at each location and $P$. coriacea at MB contained epifauna, whereas $P$. sinuosa at SS had only 6 sample bags with epifauna, and P. coriacea at SB gave only 4 replicate bags with epifauna

At SS, 3 main taxa were substantial contributors to the average dissimilarity $(89.1 \%)$ between the 2 seagrass species: harpacticoid copepods, a tanaid Apseudomorpha sp. and the family Chydoridae. Of these 3 main contributors, only harpacticoid copepods were more abundant on Posidonia sinuosa compared to Amphibolis antarctica.

At $\mathrm{SB}$, the large average dissimilarity $(91.3 \%)$ between Posidonia coriacea and Amphibolis antarctica was represented by 4 main contributors. Three of those were also the main contributing species for the dissimilarity at SS (i.e. Apseudomorpha sp., harpacticoid copepods and Chydoridae), with Polyplacophora sp. 1 contributing most to the average dissimilarity at SB. Other important contributing species were a limpet Asteracmea sp. and a member of the family Mesanthuridae. Of these 6 species, only harpacticoid copepods were more abundant in $P$. coriacea than A. antarctica.

PERMANOVA for MB revealed no significant difference between Amphibolis antarctica and Posidonia coriacea. At SS, PERMANOVA revealed a significant difference in the total assemblage between $P$. sinuosa and $A$. antarctica $(\mathrm{p}=0.001)$. At $\mathrm{SB}$, there was a significant difference in the epifaunal assemblage between $P$. coriacea and A. antarctica $(\mathrm{p}=$ $0.001)$. At $\mathrm{SB}$, the exact effect of species varied from patch to patch $(p=0.04)$ and also amongst patches nested within sites $(p=0.022)$.

There was a strong distinction between the epifaunal assemblage between seagrass species at MB (Fig. 3a), where all replicate samples contained epifauna. The MDS ordination plots of epifaunal assemblages for SS and SB showed a clear distinction between the respective seagrass species (Fig. 3b,c), but these plots did not include any samples that yielded no epifauna. This occurrence metric, in itself, can provide insight into the different assemblages. All samples of Amphibolis antarctica at every location yielded some epifauna, as did Posidonia coriacea at $\mathrm{MB}$, but a total of 12 and 14 replicate bag samples (out of 18 each) of $P$. sinuosa and P. coriacea at SS and $\mathrm{SB}$, respectively, showed a complete lack of epifauna (Fig. 3b,c), demonstrating that the epibiotic assemblages on Posidonia spp. were much sparser at SS and SB than at MB. All samples at MB, however, contained epifauna, regardless of seagrass species.

\section{Epiphytes}

Epiphytes occurred on all leaves of each species in every sample. Each of the 72 epiphytic algal morphospecies distinguished was classified into the functional groups outlined above; another 19 morphospecies were allocated into the faunal functional group. The most diverse functional group of algae contained 41 species of corticated macrophyte; there were 16 species of foliose algae, 11 species of filamentous algae, 3 species of articulated coralline algae and a single species of corticated macrophyte.

Mean epiphytic functional group richness was higher on Amphibolis antarctica across all locations with monospecific patches, compared to either Posidonia sinuosa or P. coriacea (Fig. 2c). However, in heterospecific patches at $\mathrm{MB}$, epiphytic functional group richness was higher on P. coriacea (Fig. 2c). Monospecific patches of $A$. antarctica showed the 

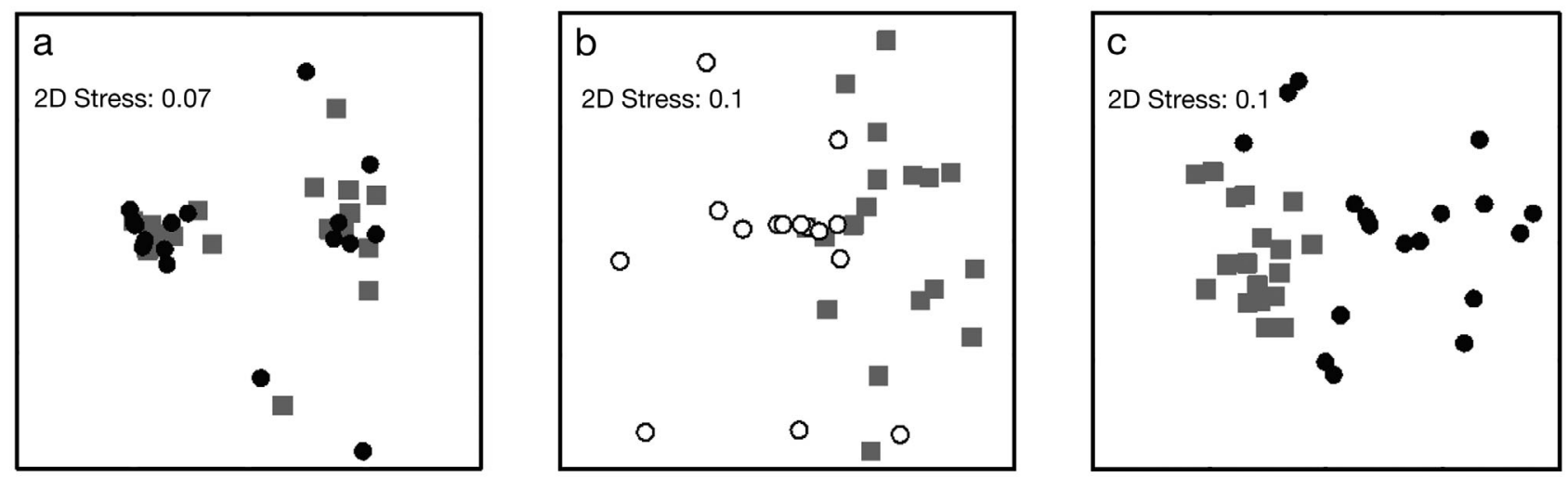

Fig. 4. Amphibolis antarctica (grey squares), Posidonia coriacea (black circles), and P. sinuosa (white circles). Multi-dimensional scaling (MDS) ordination plots of the epiphytic assemblages compared between A. antarctica and (a) P. coriacea at Maslin Beach, (b) P. sinuosa at Silver Sands, and (c) P. coriacea at Sellicks Beach. Raw data were standardised and log( $x+1)$ transformed. All replicate bag samples contained epiphytes ( $\mathrm{n}=18$ per seagrass species per location)

highest mean epiphyte abundance across all locations (Fig. 2d), with significantly more than on Posidonia coriacea at SB and more than on P. sinuosa at SS. At MB, A. antarctica had higher mean epiphytic abundance, but this was not significantly different from the abundance of epiphytes on $P$. coriacea.

\section{Multivariate analysis of epiphytes}

The MDS analyses showed no separation of the epiphytic assemblages of MB (Fig. 4a) or SS (Fig. 4b) between the pairs of seagrass species at those locations. For SB (Fig. 4c), the MDS showed a moderate separation of the epiphytic assemblages when grouped by seagrass species. The MDS plots for all sites had acceptable stress values of either 0.07 (MB) or 0.1 (SS, SB).

SIMPER analysis revealed 3 main functional groups that contributed to the average dissimilarity $(57.5 \%)$ between the 2 seagrass species found at $\mathrm{MB}$, Posidonia coriacea and Amphibolis antarctica: corticated macrophytes, fauna and filamentous algae. Of these 3 , only corticated macrophytes showed greater occurrence on $A$. antarctica.

At SS, SIMPER analysis revealed that 2 functional groups contributed consistently to the average dissimilarity (32.4\%) between Posidonia sinuosa and Amphibolis antarctica: foliose algae and corticated macrophytes. Both functional groups were more abundant on $A$. antarctica than on $P$. sinuosa.

At $\mathrm{SB}, 3$ functional groups contributed to the average dissimilarity $(43.0 \%)$ between seagrass species. Of the 3 functional groups, Posidonia coriacea had more filamentous algae, whereas foliose algae and corticated macrophytes were more abundant on Amphibolis antarctica.

At MB, PERMANOVA (with Monte Carlo testing) revealed that epiphytic functional groups varied among sites and patches, $\mathrm{p}(\mathrm{MC})=0.003$ and $\mathrm{p}(\mathrm{MC})$ $=0.02$, respectively, but not between Posidonia coriacea and Amphibolis antarctica. PERMANOVA for SS revealed no significant difference for any interaction, including between patches, sites and the 2 seagrass species, $P$. sinuosa and A. antarctica. At SB, there was a significant difference between $P$. coriacea and $A$. antarctica ( $\mathrm{p}=0.0215)$, but the exact effect varied from patch to patch, due to a significant interaction of patches with species $(p=0.032)$.

\section{DISCUSSION}

Although our samples of seagrass only covered the distal ends of plant leaves, they yielded a diverse epibiota. Epifaunal species from the phylum Crustacea, including harpacticoid copepods, a chydorid cladoceran and Apseudomorpha sp., were found to contribute to observed differences between seagrass species in all 3 locations. The chiton (Polyplacophora) also contributed to observed differences at several locations. Epiphytic functional groups, including corticated macrophytes, foliose algae and filamentous algae, all contributed consistently across sites.

This research demonstrates differences among 3 local seagrass species, Posidonia coriacea, P. sinuosa and Amphibolis antarctica, in regards to their associated epibiotic assemblages. Although this is a preliminary study, which did not include a temporal aspect in its design, these findings also yielded 
contrasting patterns between 2 patch arrangements, hetero- and monospecific beds, for 1 pair. More examples of such arrangements should be studied in future.

The design of this study allowed the comparison of epibiota between pairs of the seagrass species, including one contrast of monospecific with heterospecific patches (albeit across different locations but with the same pair of seagrass species). Previous studies of epibiota, like those of MacArthur \& Hyndes (2001) and Hyndes et al. (2003), did not encounter heterogeneous patches, and so were confined to comparing monospecific patches of a single species at a time.

Motile epifaunal species showed a clear preference for the structurally complex Amphibolis antarctica where it shared patches with the simpler Posidonia coriacea (at SB) or P. sinuosa (at SS). Epifaunal species richness and abundance in $P$. coriacea fell noticeably when sharing patches with $A$. antarctica. Where segregated, patches of $P$. coriacea showed no significant difference in assemblage from patches of A. antarctica at the same location. These results must, however, be interpreted with some level of caution because these patch types themselves occurred in separate locations (MB and SB, respectively). This may suggest that mobile epifauna show habitat selection via movement over small scales within patches but will live in a wide range of seagrasses when choice is limited. Therefore, predicting epifauna requires an understanding of what seagrass species are where, and also how, they are arranged in localised patches.

Structural complexity may not be the only driving factor behind the epifaunal preference towards Amphibolis antarctica. Epiphytic assemblages also showed a clear preference for the leaves of $A$. antarctica, which in turn may attract motile epifauna (Edgar 1991, Bologna \& Heck 1999, Bostrom \& Mattila 1999), e.g. for food, further increasing epibiotic assemblages. However, due to the preliminary and purely descriptive nature of this biological survey, we suggest that further complementary sampling and manipulative experiments (e.g. giving choices to some epibiotic taxa across seagrass species) are needed to elucidate the mechanisms behind such observed differences.

PERMANOVA revealed significantly different epifaunal assemblages between 2 species of seagrass sharing the same patch at SS and SB but not between 2 species when separated into monospecific patches (at $\mathrm{MB}$ ). The result for $\mathrm{MB}$ is surprising, given the strong dissimilarity between the epifaunal assem- blages associated with either seagrass species, shown in ordinations. The PERMANOVA test for MB did have only a small number of available permutations (unique permutations $=10$ only), meaning that very few unique values of the test statistic were obtained, reducing our ability to make inferences about the $\mathrm{p}$ value, even with Monte Carlo testing (Anderson et al. 2008). We would therefore need to increase the number of samples to include more seagrass species, or include more sites to increase the power to detect species differences.

Borowitzka et al. (2006) suggested that epiphyte assemblages can vary significantly across different spatial scales, from tens of metres to between patches. However, Moore \& Fairweather (2006) found that mean epiphytic biomass remained relatively homogeneous at a local $(<100 \mathrm{~m})$ scale in South Australia (because assemblages were quite variable at all scales). We found that the epiphytic assemblage varied significantly from patch to patch $(\mathrm{p}=0.02$ and 0.032 at $\mathrm{MB}$ and $\mathrm{SB}$, respectively) and from site to site $(p=0.0215)$ at $M B$, representing great smallscale variation.

We therefore conclude that the potential of one seagrass to act as a surrogate for the epibiotic assemblage of another is poor, with each seagrass species showing a high level of specificity of epibiota when found in heterospecific patches. This study is the first to show both effects of species identity and arrangement simultaneously and thus has broad implications for conservation agencies that use broad-scale habitats as surrogates for biodiversity (Rodrigues \& Brooks 2007), where more than 1 seagrass species may be present. Marine reserve planning thus needs to consider seagrass habitat on a species-by-species basis, including how each species is arranged within localised patches, to be sure to capture the biodiversity of epibiota underlying such gross habitat patterns.

Acknowledgements. We thank R. Quin, T. Ramsdale, R. Lester, D. Fogarty, S. Duong and J. Lill for support and Y. Eglington, D. Miller, J. Brook, R. Baring and R. Gannon for assistance in the field and laboratory. Funding from Flinders University and logistic support from the Department of Environment \& Natural Resources is gratefully acknowledged. Comments by 3 anonymous reviewers greatly improved the manuscript.

\section{LITERATURE CITED}

Anderson MJ, Gorley RN, Clarke KR (2008) PERMANOVA+ for PRIMER: guide to software and statistical methods. PRIMER-E, Plymouth

Bologna PAX, Heck KL (1999) Macrofaunal associations 
with seagrass epiphytes: relative importance of trophic and structural characteristics. J Exp Mar Biol Ecol 242: 21-39

Borowitzka MA, Lavery PS, van Keulen M (2006) Epiphytes of seagrass. In: Larkum AWD, Orth RJ, Duarte CM (eds) Seagrasses: biology, ecology and conservation. Springer, Dordrecht, p 441-461

Bostrom C, Mattila J (1999) The relative importance of food and shelter for seagrass-associated invertebrates: a latitudinal comparison of habitat choice by isopod grazers. Oecologia 120:162-170

Bramwell MD, Woelkerling WJ (1984) Studies on the distribution of Pneophyllum-Fosliella plants (Corallinaceae, Rhodophyta) on leaves of the seagrass Amphibolis antarctica (Cymodoceaceae). Aust J Bot 32:131-137

Bryars S, Wear R, Collings G (2008) Seagrasses of Gulf St. Vincent and Investigator Strait. In: Shepherd SA, Bryars S, Kirkegaard I, Harbison P, Jennings JT (eds) Natural history of Gulf St. Vincent. Royal Society of South Australia, Adelaide, p 132-147

Clarke KR, Gorley RN (2006) PRIMER v6: user manual/tutorial. PRIMER-E, Plymouth

> Duffy JE (2006) Biodiversity and the functioning of seagrass ecosystems. Mar Ecol Prog Ser 311:233-250

Edgar GJ (1991) Artificial algae as habitats for mobile epifauna: factors affecting colonization in a Japanese Sargassum bed. Hydrobiologia 226:111-118

Edgar GJ (2001) Australian marine habitats in temperate waters. Reed New Holland Publishers, Sydney

Gobert S, Cambridge ML, Velimirov B, Pergent G and others (2006) Biology of Posidonia. In: Larkum AWD, Orth RJ, Duarte CM (eds) Seagrasses: biology, ecology and conservation. Springer, Dordrecht, p 387-408

Hemminga MA, Duarte CM (2000) Seagrass ecology. Cambridge University Press, Cambridge

Hirst AJ (2008) Surrogate measures for assessing cryptic faunal biodiversity on macroalgal-dominated subtidal reefs. Biol Conserv 141:211-220

Hughes AR, Williams SL, Duarte CM, Heck KL Jr, Waycott M (2009) Associations of concern: declining seagrasses and threatened dependent species. Front Ecol Environ 7: 242-246

Hyndes GA, Kendrick AJ, MacArthur LD, Stewart E (2003) Differences in the species- and size-composition of fish assemblages in three distinct seagrass habitats with differing plant and meadow structure. Mar Biol 142: 1195-1206

Jernakoff P, Nielsen J (1998) Plant-animal associations in

Editorial responsibility: Hans Heinrich Janssen, Oldendorf/Luhe, Germany two species of seagrasses in Western Australia. Aquat Bot 60:359-376

Jones CG, Lawton JH, Shachak M (1994) Organisms as ecosystem engineers. Oikos 69:373-386

Kendrick GA, Lavery PS (2001) Assessing biomass, assemblage structure and productivity of algal epiphytes on seagrasses. In: Short FT, Coles RG (eds) Global seagrass research methods. Elsevier Science, Amsterdam, p 199-222

> Lavery PS, Vanderklift MA (2002) A comparison of spatial and temporal patterns in epiphytic macroalgal assemblages of the seagrasses Amphibolis griffithii and Posidonia coriacea. Mar Ecol Prog Ser 236:99-112

MacArthur LD, Hyndes GA (2001) Differential use of seagrass assemblages by a suite of odacid species. Estuar Coast Shelf Sci 52:79-90

- McArthur LC, Boland JW (2006) The economic contribution of seagrass to secondary production in South Australia. Ecol Model 196:163-172

> Moore TN, Fairweather PG (2006) Lack of significant change in epiphyte biomass with increasing extent of measurement within seagrass meadows. Estuar Coast Shelf Sci 68:413-420

Orth RJ, Carruthers TJB, Dennison WC, Duarte CM and others (2006) A global crisis for seagrass ecosystems. BioScience 56:987-996

Raz-Guzman A, Grizzle RE (2001) Techniques for quantitative sampling of infauna and small epifauna in seagrass. In: Short FT, Coles RG (eds) Global seagrass research methods. Elsevier Science, Amsterdam, p 237-253

Rodrigues ASL, Brooks TM (2007) Shortcuts for biodiversity conservation planning: the effectiveness of surrogates. Annu Rev Ecol Evol Syst 38:713-737

Steneck RS, Dethier MN (1994) A functional groups approach to the structure of algal-dominated communities. Oikos 69:476-498

Trautman DA, Borowitzka MA (1999) Distribution of the epiphytic organisms on Posidonia australis and P. sinuosa, two seagrasses with differing leaf morphology. Mar Ecol Prog Ser 179:215-229

> Vanderklift MA, Lavery PS (2000) Patchiness in assemblages of epiphytic macroalgae on Posidonia coriacea at a hierarchy of spatial scales. Mar Ecol Prog Ser 192: 127-135

- Waycott M, Duarte CM, Carruthers TJB, Orth RJ and others (2009) Accelerating loss of seagrasses across the globe threatens coastal ecosystems. Proc Natl Acad Sci USA 106:12377-12381

Submitted: February 1, 2010; Accepted: February 2, 2012 Proofs received from author(s): May 6, 2012 